\title{
PAST, PRESENT AND FUTURE OF THE SPECIALISED SERVICE FOR SPINAL CORD SUFFERERS
}

\author{
Sir Ludwig Guttmann, C.B.E., F.R.S. \\ Aylesbury, England
}

RECOLLECTIONS from the past of the treatment and prognosis of spinal paraplegics, let alone tetraplegics, as the result of traumatic or non-traumatic spinal cord afflictions revive depressing memories of hopelessness and helplessness. One remembers men, women and children with sallow complexions, apathy and drowsiness, emaciated from septic absorption from smelling pressure sores and urinary infection, tetraplegics dying within hours or a few days from pulmonary collapse or other early lung complications. Throughout the centuries, the medical profession seemed to be possessed by the idea that nothing or little could be done for these unfortunate members of the community. They did not present a social problem as their life expectancy was minimal, and the few who did survive were thrown on the human scrap heap into institutions or hospitals for incurables with no incentive or facilities for a life of activity and purpose. It is essential to remind ourselves and society of these dark times, who today in many countries take the modern approach to this complex problem of medicine and humanity for granted.

Since the introduction of the concept of comprehensive management and research in spinal injury centres (which developed at the later stages of and after World War II), the synthesis between all medical and surgical procedures and all measures of domestic and social resettlement of these patients, based on the principles of modern rehabilitation, has accomplished a dramatic change in the outlook of spinal paraplegia as well as tetraplegia. Throughout the world, spinal centres are growing in numbers. They have accepted the concept of comprehensive management of traumatic paraplegia and tetraplegia which includes all aspects of this complex subject of medicine and surgery from the start and throughout all stages. It rejects the hitherto practised fragmentation of the initial treatment in general hospitals and long-term management of these patients in spinal centres.

Today, preventive medicine and promotion of good health is generally accepted as a philosophy of the medical profession, health authorities, politicians and governments concerned with the welfare of people in the community. Can we, as members of the International Medical Society of Paraplegia, be satisfied that this applies to spinal cord sufferers and that the remarkable achievements made by spinal injuries centres during the last 30 years are safeguarded for the future?

In my Harben Lecture, published in 1977 in the journal of the Royal Institute of Public Health and Hygiene 'On Health Deviation and Rehabilitation in Spinal Paraplegia and Tetraplegia', I expressed some concern about the future of the specialised service of spinal paraplegia and tetraplegia. Moreover, in a paper recently published in Paraplegia (Guttmann, 1977-78) I have reminded surgeons and physicians concerned with the emergency and initial treatment of spinal cord injuries admitted first to accident, neurosurgical and orthopaedic departments of general hospitals, and because of circumstances not immediately to spinal injuries centres, of certain key responsibilities in dealing not merely with the treatment of 
the injured spine and spinal cord but also with all other aspects of the injured human being.

During the last 15 years, our journal has been doing much to further and disseminate knowledge as the result of research in the many aspects of this multidisciplinary problem. Therefore, I welcomed the request of my colleagues and friends, Jim Cosbie Ross and Phillip Harris, who have undertaken the editorship of the 1979 May issue of Paraplegia, to air my views in this issue on the future of the service of paraplegia and tetraplegia, which, I feel, is also closely connected with the future of our International Medical Society of Paraplegia.

\section{Need for increase of Spinal Injury Centres}

Are there enough specialised centres to cope with the ever increasing number both of paraplegics and, in particular, tetraplegics? The answer is a clear 'No'. Some countries have accommodated themselves to this need by increasing the number of spinal centres, and amongst the many nations Germany has made great strides during the last 20 years as have Australia, Czechoslovakia, Israel, Poland, Singapore, South Africa and, in recent years, the U.S.A., where Regional Spinal Centres for civilians have been set up. On the other hand, other countries have remained stagnant, amongst them-alas-Great Britain which pioneered the setting up of spinal centres during and after World War II and where the concept of comprehensive management and research of spinal paraplegia and tetraplegia originated.

When I retired from the Directorship of the National Spinal Injuries Centre at Stoke Mandeville, there were no less than I 90 beds available for the clinical management in the Centre, and in addition 30 beds in a hostel for those tetraplegics and severely handicapped paraplegics who, for one reason or another, were not able to return home or had to be readmitted when the families were no longer able to look after them at home. This hostel, which has been recently rebuilt and enlarged to 40 beds by including Io beds for non-spinal young disabled patients, is still the only one in Great Britain. However, in recent years, the number of clinical beds of the Centre has been reduced to a current I 54 by the policy of the Oxford Regional Health Authority, which indeed intended to reduce the Centre even further to 120 beds. This was done even though the waiting list for new cases and readmission of former patients for check-ups or specialised treatment has not diminished-on the contrary it is in fact still very large. Last year, 229 new patients were admitted to the Centre, about the same number as when the Unit had I90 beds, but 40 new patients remained on the waiting list; amongst them were I I who, although acute injuries originally, could not be admitted for a long time, whilst there were 50 former patients on the waiting list for readmission. In this connection, it may be noted that other Spinal Units such as Southport and Oswestry have reported difficulties in disposing of patients ready for discharge, which naturally diminishes their capacity for new admissions and readmissions. The results of this incomprehensible policy on the part of Regional Health Authorities are only too obvious. In the first place, any delay in giving new traumatic paraplegics and, in particular, tetraplegics a comprehensive specialised treatment from the start must necessarily revert to the bad old times when these unfortunate people were admitted to Spinal Centres at later dates with most serious complications necessitating prolonged inpatient treatment, resulting not only in considerable increase in costs but also irreversible damage to the organism caused by inadequate initial management elsewhere. In this respect, Great Britain does not stand alone, and I refer to a 
report published some years ago by Jacobson and Bors (1970) on the tragic consequences of delay in admission of spinal cord casualties from the Vietnam combat, which speaks for itself and fully confirms my anxiety about the present situation in this and other countries.

The other unfortunate result of the shortage of beds for a comprehensive service for spinal cord sufferers is that treatment and rehabilitation may have to be curtailed and the patients discharged prematurely, and it may well lower the standard of management if patients are discharged physically more or less fit but psychologically and socially not readjusted to cope with the activities of their new life-style in the world around them.

Since 1967, negotiations have been held between leaders of Spinal Centres and the Authorities of the Department of Health of the Government in Great Britain, when the need to increase the number of Spinal Units has been stressed. Moreover, the Tunbridge Report on Rehabilitation, realising this need, also recommended an increase of two additional spinal units. However, nothing has emerged so far, except the Ministry of Health's statement that in the early '8os a new Spinal Unit will be set up in the South of England to relieve the pressure on the Stoke Mandeville National Spinal Injuries Centre. Even if this materialises (and it will take at least 4-5 years for the new unit to be working to full capacity), this is indeed cold comfort for the many new spinal cord sufferers in the intervening years! Moreover, even if this Unit is established, this will bring the number of beds available in Great Britain to approximately the original number of beds of 1966 . It is beyond this paper to go in detail into the background of this unfortunate policy of the Regional Health Authority, but to increase the number of beds for other hospital services at the cost of beds for spinal cord injuries is really indefensible. In view of numerous protests made against this action, it was the Prime Minister Mr Callaghan's personal intervention that a further reduction of beds at Stoke Mandeville Centre was stopped. The Stoke Mandeville National Spinal Injuries Centre is by no means an isolated case in experiencing difficulties with the administration of Regional Health Authorities. Some years ago, the former consultant in charge of the Spinal Centre in Southport battled for better facilities for the Unit, including its transfer to a newly set up hospital in Fazakerley, Liverpool, with excellent facilities, but this was turned down by the regional administration. He finally became so frustrated that he resigned. It is no consolation that in other countries similar difficulties with local or regional crass officialdom have been experienced. How far the International Medical Society of Paraplegia might be able to help in this struggle for the future of the spinal cord service by making representations to Governments remains to be seen, but we should not fail for want of trying.

\section{Lack of Official Recognition of Paraplegia and Tetraplegia as a Specialty}

The lack of official recognition of this service, which for many years de facto has been a specialty of its own, is detrimental to the future development of this complex branch of medicine and surgery. If this service were to be recognised by the Department of Health and the Colleges of Physicians and Surgeons and the Universities were to establish a career structure, it would attract suitable younger medical men to take up this specialty as their life's work, as the founders of this special service have done. Otherwise, younger colleagues who are genuinely interested in this de facto specialty cannot see any future for their career. This was 
formerly the case with other specialties concerned with the treatment and management of special organs, such as Chest medicine and surgery, ENT, Ophthalmology, Dermatology, etc. In my long medical career, I have witnessed the struggle of neurology, which previously was either part of general medicine or psychiatry, to be recognised as a specialty on its own. The same applies to neurosurgery and orthopaedic surgery, which previously were part of general surgery. It was through their specialisation that these specialties have made great contributions to mankind. It seems, therefore, ironical that Great Britain, where the modern concept of treatment and rehabilitation of spinal cord sufferers was pioneered and which is now recognised and accepted in other countries, is sadly lagging behind others in this official recognition. To give some examples: it was the University of Heidelberg which appointed a specialist of Paraplegia, Professor Volkmar Paeslack as Ordinarius (Professor of a Chair) of Rehabilitation. This was followed by Harvard University at Boston which appointed Dr Alain Rossier, the Director of the Spinal Injuries Centre at West Roxbury and himself a paraplegic, as Professor of Spinal Injuries and Social Medicine. Similar situations exist in Belgium and Poland. Moroever, spinal injuries centres in Basle and Geneva (Switzerland), Perth, Sydney, Melbourne, Adelaide and Brisbane (Australia), Chicago (U.S.A.), and Toronto (Canada) are attached to University Hospitals. I feel it is one of the responsibilities of I.M.S.P. to make the appropriate representation to Governments and Medical Authorities in this respect.

\section{Directorship of a Spinal Injuries Centre or Chairmanship of a Departmental Committee?}

When the special spinal cord injury service was originally set up in World War II in Great Britain, the spinal units were attached mainly to neurosurgical and orthopaedic departments. This arrangement proved as a rule very unsatisfactory, the medical and paramedical staff of these specialties being so busy with the many other afflictions in their own specialties that, as a rule, it was quite impossible for them to give spinal cord sufferers that meticulous care and attention to detail which these patients need day and night, especially during the immediate and early stages. There did not appear to be any definite plan or end in view for the rehabilitation of even the more fit patients. T. B. Dick (1949) has given an excellent account of the unsatisfactory conditions prevailing in one of the first spinal units attached to a neurosurgical department at that time, and my own observations, which I made during visits to other spinal units attached to orthopaedic departments at the request of the Ministry of Pensions, were in fullest accordance with Dick's report. This unfortunate situation changed fundamentally only when spinal units became independent centres and their supervision given to an experienced physician or surgeon prepared to give up part of his own specialty in order to devote his full time to this specialised service, which demands meticulous attention to detail. Whether his official designation was that of Director or Consultant-in-Charge was irrelevant, but as head of the unit he had the ultimate responsibility for all patients of the unit. His task was to plan, organise and coordinate the many details of treatment with his team of medical and paramedical co-workers and, lastly but by no means least, to correlate the sometimes conflicting interests of visiting medical and surgical specialists concerned with special aspects of treatment. In larger spinal units, such as the Stoke Mandeville National Spinal Injuries Centre a secretary-administrator was employed who worked in close concert with the Clinical Director, and Miss Joan Scruton, M.B.E., the first to be appointed at Stoke Mandeville, was eventually 
upgraded to the rank of a Deputy Administrator of the hospital. Throughout the years, specific duties and functions were delegated to senior members of the medical and paramedical staff. This structure has worked very well in the unified concept of management and treatment at Stoke Mandeville, as it has done in other spinal centres, and has been really responsible for the organic development and great success of spinal centres in Great Britain and abroad.

I am aware that the authority of leadership is sometimes misconstrued as autocracy and even dictatorship by some people of our profession, who obviously cannot appreciate the true meaning of these, particularly of the latter. The fact remains that the previous system of leadership, which naturally applied to any other type of special medical or surgical services, proved, as a rule, to be highly successful as far as the patients themselves were concerned and also essential in the guidance of the paramedical staff-nurses, physiotherapists, occupational therapists, social workers etc.- - who always could turn to the head of the department in matters of uncertainty and confusion. Alas-in recent years with all the huffing and puffing of an inflated administrative apparatus of the Health Service in reorganising their great service in Britain, there has emerged a policy to replace the clinical leadership of specialised services such as Spinal Injuries Centres on the ruling of medical administrators of Regional Health Authorities. It is ironical that, while the Senior Medical Administrator remains in charge of his or her senior and junior colleagues of the medical administration, this is now being denied to the heads of clinical services, who no longer have the ultimate responsibility for all patients of their specialised department. Instead, the previous Consultant-in-Charge or Director of the unit is now transformed into a Chairman of a clinical departmental committee, the chairmanship of which is changed every 2 years, who merely acts as an intermediary between his committee and the medical administrative department of the Regional Health Authority, without having the ultimate responsibility for all patients of his specialised service or any jurisdiction of the senior as well as junior medical staff. Moreover, the senior nursing staff is also ruled by groups of nursing administrators. I deplore this bureaucratic policy of the medical administration of Regional Health Authorities (apparently accepted by the Ministry of Health without consultation with the senior clinicians and senior members of the paramedical staff involved but with consultation with 'other interested parties'), as being a fundamental error, and, indeed, unfair. Dissension amongst the senior medical members must in future lead to resentment and frustration of the staff of the Unit and dissolution of a unified treatment and management of the specialised service, with consequently detrimental effects on the patients.

\section{The Attitude of the Community}

What is the attitude today of the community at large towards the victims of spinal cord injuries and disease ? There is no doubt that the public as a whole have become more aware of their responsibilities towards these severely disabled fellowmen in wheelchairs. However, in spite of pious resolutions passed unanimously by the United Nations on 'The Rights of the Disabled', 1975, and in Great Britain by the legislation of the Chronically Sick and Disabled Persons Act, the practical application of these charters of humanity still leaves much to be desired.

In the repeatedly changing pattern of life in the community, even some of the able-bodied have difficulty in adapting to innovations and changes in the hustle of daily community living. How much more difficult then must this be to the severely disabled in wheelchairs, considering the existing architectural barriers in public 
buildings, museums, theatres, sports and leisure centres, exhibition buildings and even houses. The same applies to the problem of transport. It is indeed most deplorable that in our present time with all the advances in transport, people in wheelchairs when travelling by train have still to travel not infrequently in the guard's van along with goods and animals, unless voluntary helpers have lifted them into the passenger carriage. I remember a film made in Switzerland, where two paraplegics had to travel in a guard's van in the company of a pig! Although improvements have certainly been made in adjusting houses by the installation of ramps and handrails, widening of doorways, adjusting toilets and bathrooms etc., public buildings such as libraries, post offices, banks, shops etc. still present all too often insurmountable barriers to a severely disabled person, particularly one in a wheelchair. Recently in this country, special shopping centres have been built in many cities and towns for pedestrians only to avoid the congestion of traffic, and here it is especially important that the disabled should have parking places in the closest proximity, so that they can reach the shopping centres easily in their wheelchairs. It is gratifying to note that, at least in some towns in this and other countries, special provisions for parking places and public toilets for wheelchair users and other severely disabled citizens (for instance in airports) are being provided. However, there is still much to be desired in this respect, and here again our International Society could play an active part by making a special research into this problem.

\section{REFERENCES}

DICK, T. B. (1949). Rehabilitation in chronic paraplegia. M.D. Thesis, Manchester University.

Dick, T. B. (I969). Traumatic paraplegia pre-Guttmann. Paraplegia, 7, I73.

GUTTMANN, L. (1977). On health deviation and rehabilitation in spinal paraplegia and tetraplegia-Harben Lecture. Community Health, 8, i86.

GutTMANN, L. (1977/78). Total responsibility of the surgeon in the management of traumatic spinal paraplegics and tetraplegics. Paraplegia, 15, 285.

Jacobson, S. A. \& BoRS, E. (1970). Spinal cord injury in Vietnamese combat. Paraplegia, 5, II5. 